This item was submitted to Loughborough's Research Repository by the author.

Items in Figshare are protected by copyright, with all rights reserved, unless otherwise indicated.

\title{
Porosity in multi-axis material extrusion of short-fibre composites
}

PLEASE CITE THE PUBLISHED VERSION

https://doi.org/10.1108/RPJ-02-2020-0035

PUBLISHER

Emerald

VERSION

AM (Accepted Manuscript)

PUBLISHER STATEMENT

This paper was accepted for publication in the journal Rapid Prototyping Journal and the definitive published version is available at https://doi.org/10.1108/RPJ-02-2020-0035

\section{LICENCE}

CC BY-NC 4.0

\section{REPOSITORY RECORD}

Kaill, Nathaniel, Robert Campbell, and Patrick Pradel. 2021. "Porosity in Multi-axis Material Extrusion of Shortfibre Composites”. Loughborough University. https://hdl.handle.net/2134/13341095.v1. 


\section{Porosity in Multi-Axis Material Extrusion of Short-Fibre Composites}

\begin{tabular}{|r|l|}
\hline Journal: & Rapid Prototyping Journal \\
\hline Manuscript ID & RPJ-02-2020-0035.R2 \\
\hline Manuscript Type: & Original Article \\
\hline Keywords: & $\begin{array}{l}\text { Additive Manufacturing, Composites, Short Fibre Composites, Multi-Axis } \\
\text { Material Extrusion }\end{array}$ \\
\hline \multicolumn{2}{|l}{} \\
\hline
\end{tabular}

\section{SCHOLARONE \\ Manuscripts}




\title{
Porosity in Multi-Axis Material Extrusion of Short-Fibre Composites
}

\author{
Abstract \\ Purpose - This study aims to investigate the relationship between part porosity and \\ mechanical properties of short-fibre reinforced PLA printed via Multi-Axis Material Extrusion \\ (MAMEX) to establish guidelines for optimal process configurations.
}

Design/methodology/approach - Material properties graphs provide the basis for studying the relationship between porosity and mechanical behaviour. Using the correlations found in this study, the way to improve printing strategies and filament properties can be deducted directly from an analysis of the print path and the final influence on mechanical performance.

Findings - Some commercial brands of short-fibre reinforced filament present inherent porosity that weakens the mechanical behaviour of MAMEX components.

Originality/value - Low-cost MAMEX allows the production of components that do not present anisotropic behaviour and are mechanically optimised through the alignment of the filaments along with internal stresses. This paper also addresses the effects of multi-axis deposition strategies on the resulting porosity and proposes improvements to reduce residual porosity, thus increasing the mechanical performance in the future.

Keywords: Short-fibre composites, multi-axis material extrusion, material extrusion

Paper type: Research paper

\section{Introduction}

Since its introduction in 1980 (Wang et al., 2017), material extrusion (MEX), also referred to by the Stratasys trade name Fused Deposition Modeling (FDM), has gained widespread acceptance and a large user-base among additive manufacturing (AM) technologies for the processing of polymers (Ning et al., 2017; Wang et al., 2016).

In MEX, 3D parts are built by depositing a semi-liquid thermoplastic filament layer by layer. The thermoplastic filament is heated to a glass transition state and extruded through a nozzle at a constant temperature. The extrusion nozzle moves in the XY plane depositing the desired material onto the build platform according to a tool path generated by the software. When a layer is completed, the build platform moves downward by one-layer thickness and the nozzle extrudes the material for the following layer. Every single layer is deposited repeatedly on the previous one until the part is completed (e.g. Blok et al., 2018; Mei et al., 2019; Ning et al., 2017; Papon and Haque, 2019; Wang et al., 2017). The characteristics of MEX parts can be influenced by different printing parameters such as layer thickness, printing orientation, raster width, raster angle and air gap, fused line deposition height, type of internal microstructure, extrusion temperature, ambient or environmental temperatures and presence and configuration of external walls (Ahn et al., 2002b; Ferreira et al., 2017; Vaezi and Yang, 2015; Wang et al., 2017; Zhang et al., 2018).

In addition to the advantages common to all AM technologies such as shape complexity (Zhang et al., 2018), part consolidation (McLouth et al., 2017a), mass customisation (Zhang 
et al., 2018), minimum waste (Mei et al., 2019), no need for auxiliary tooling (Papon and Haque, 2019), MEX has a lower energy consumption, locally controlled properties (e.g. porosity, density and mechanical properties) (Sun et al., 2008), less expensive machines and materials (Al Abadi et al., 2018; Zhang et al., 2018), and no need for chemical postprocessing (Naranjo-Lozada et al., 2019; Ning et al., 2017). These characteristics result in a process that is both simple and cost-effective.

These characteristics have largely contributed to the significant adoption of MEX (Hoglund and Smith, 2015; Koch et al., 2017a; McLouth et al., 2017a; Shen et al., 2018a; Tekinalp and $\mathrm{Al}, 2014)$. The range of MEX end-use applications extends over different fields. Some examples include medical devices (Moetazedian et al., 2020; Mohammed and Fay, 2018; Paterson et al., 2015), sports equipment (Lithgow et al., 2019), automotive (Carlota, 2019), nautical (Carlota, 2019), furniture (Novak and O'Neill, 2019), heavy machinery (Lee, 2019), lighting ("Gantri", 2018), etc.

However, compared to traditionally manufactured parts and other AM processes, MEX parts suffer from limitations such as poor surface quality and poor mechanical properties, particularly in the z-direction (Naranjo-Lozada et al., 2019). Among those limitations, poor mechanical properties are the major restriction for wider adoption of MEX in end-use applications (Ning et al., 2017; Papon and Haque, 2019; Shofner et al., 2002; Wang et al., 2017; Zhong et al., 2001). MEX components suffer from anisotropic behaviour which limits their use to single direction loads scenarios (Ahn et al., 2002b). This is primarily due to the 2.5-dimensional nature of current MEX machines, which build parts through stacks of 2.5dimensional planar layers (Bellini and Güçeri, 2003; Blok et al., 2018). Since the interlayer bonding is weaker than the intralayer bonding (Sun et al., 2008), the tensile strength of MEX components can be significantly weaker between layers. This means that MEX components are not suitable for multidirectional stresses. To overcome this limitation, designers need to apply strategies such as part segmentation (Anwer and Naguib, 2018a; Damon et al., 2019) or compromise between mechanical performance, support structures and surface quality (Wulle et al., 2017).

Several approaches have been proposed to improve the mechanical performances of MEX components. Among those, short-fibre reinforced composites have attracted significant interest due to their easy integration into MEX material systems (Wang et al., 2017). Through the incorporation of short fibres, typically short carbon fibres (SCFs), a 3D-printed composite can demonstrate significantly improved mechanical behaviour over the base material (Anwer and Naguib, 2018b; Dickson et al., 2017; Li et al., 2016; Weon et al., 2006). For instance, Shofner et al. (2002) found that $10 \mathrm{wt} \%$ nanofiber filled ABS specimens exhibited nearly $40 \%$ and $60 \%$ increases in tensile strength and tensile modulus, respectively. Tekinalp and Al (Tekinalp and Al, 2014) have shown that SCF-reinforced ABS exhibited an increase in tensile strength and modulus of $115 \%$ and $700 \%$, respectively. Work conducted at Texas Tech University (Ning et al., 2017) discovered that incorporating carbon fibre into plastic materials can increase tensile strength and Young's modulus, but may decrease toughness, yield strength, and ductility. The tensile strength and Young's modulus of fabricated specimens could increase by $22.5 \%$ and $30.5 \%$, respectively with a $5 \mathrm{wt} \%$ or $7.5 \mathrm{wt} \%$ carbon fibre content. Compared with the pure plastic specimens, SCF-reinforced composite specimens with $5 \mathrm{wt} \%$ carbon fibre content exhibited increases in flexural stress, flexural modulus, and flexural toughness of $11.82 \%, 16.82 \%$, and $21.86 \%$, respectively. Ferreira (Ferreira et al., 2017) concluded that short carbon fibres increased the tensile 
modulus of PLA of about 2.2 times when the extrusion paths align with the direction of the tensile load, and 1.25 times when the extrusion paths are perpendicular. Conversely, tensile strength was not improved by the short carbon fibres. More recently, Papon and Haque (Papon and Haque, 2019) showed that $5 \mathrm{wt}$ \% of SCFs can increase fracture toughness and energy release rate although print orientation can significantly affect this behaviour. These results show that there is no research consensus regarding the impact of adding carbon fibres to MEX polymers.

One of the reasons for discrepancies in the results for SCF-reinforced MEX test samples could be porosity. Tekinalp and Al (Tekinalp and Al, 2014) observed significant porosity in MEX-printed samples. With increasing fibre content, voids inside the MEX-printed beads increased, while voids between the beads decreased. Although high porosity was observed in MEX-printed SCF-reinforced composite parts, they still exhibited comparable tensile strength and modulus compared to those produced by compression moulding. Ning (Ning et al., 2017) discovered that porosity becomes severe in specimens with at least $10 \mathrm{wt} \%$ carbon fibre content. The porosity trend was correlated with the fracture interface observation results. This may suggest porosity to be the reason for unexpected mechanical properties. Adding carbon fibres at $10 \mathrm{wt} \%$ resulted in the smallest mean values of tensile strength, toughness, yield strength, and ductility. Wang (Wang et al., 2017) also studied the effects of porosity on the properties of 3D-printed SCF-reinforced ABS composite parts and compared them with samples made by compression moulding. Due to the presence of gaps between deposition lines and poor bonding between polymer and fibre, the 3D printed composite samples showed significant void formation ( $20 \%)$. The voids that formed during the printing process significantly impaired the mechanical properties of the printed composites. Zhang (Zhang et al., 2018) also found an increase in porosity with the addition of fibres into ABS filament. They concluded that different raster orientations and printing materials gave rise to different microstructures and porosity.

Researchers have also investigated how to reduce void formation. Wang (Wang et al., 2016) found that including $11 \mathrm{wt} \%$ of expandable microspheres into the filament can reduce the porosity in MEX parts from $17 \%$ to $7 \%$ and hence greatly increase the mechanical properties. Conversely, Le Duigou (Le Duigou et al., 2016) suggested that voids can be exploited for controlling the hygroscopic properties of MEX components, hypothesising that 4D printing concepts can be applied to design passive hygromorph products.

Another approach that has recently received interest from the scientific and industrial communities is multi-axis MEX. Since the anisotropic mechanical behaviour of MEX is primarily due to the 2.5-dimensional nature of current MEX systems, machines with an additional number of rotational axes can provide greater manufacturing flexibility. This allows the deposition of the heated filament in a genuinely three-dimensional manner (Shen et al., 2018a). This not only has the potential to compensate for the anisotropic behaviour of MEX components but also to optimise the weight to mechanical performance ratio by aligning the fused filament and the composites fibres in the direction of the loads (Gardner et al., 2018).

The combination of SCF-reinforced filament and MAMEX has significant potential. Previous research has shown that the orientation of the bead in the load direction results in stronger MEX parts (Koch et al., 2017a) while the inclusion of axes of rotation can improve the samples' mechanical behaviour (Ahn et al., 2002a; Gardner, 2018; Koch et al., 2017b; McLouth et al., 2017b; Shen et al., 2018b; Zhang et al., 2016). There has also been evidence that SCFs can be aligned along the deposition direction thus further increasing the 
components' mechanical behaviour (Ferreira et al., 2017; Shofner et al., 2002; Tekinalp and Al, 2014).

To date, few studies have explored the mechanical behaviour of MAMEX short-fibre composites, although this technique can overcome the main limitation of MEX (Kaill et al., 2019). As far as the authors are aware, little to no previous work has been observed on the impact of porosity on MAMEX part properties.

This paper specifically aims to investigate and determine the impact of porosity within the deposited material when extruded through a MAMEX system. As AM moves towards enduse manufacturing, materials of varying quality are likely to be used. Therefore, two different makes of SCF-reinforced polylactic acid (SCF-PLA) filaments were used for the investigation. Dome structures were used as sample geometries to test a fully 3-dimensional tool path, which incorporated 3-axes of linear motion and two axes of rotational motion. Finally, the mechanical behaviour of SCF-reinforced wave spring parts was analysed.

The remainder of the article is organized as follows. Section 2 presents the characteristics of the materials tested, the geometric parameters evaluated, and the fabrication and characterization equipment. Section 3 presents the tensile property results, as well as the mesostructure and fatigue mechanism analyses for the specimens produced. Discussion of the results is also presented. Section 4 describes some implications for part design and summarizes the conclusions and future work.

\section{Methodology}

\section{Sample design and part-programming}

Two sets of samples were created to test the different filaments in this study, a wave spring part and a dome part. The purpose of these two sets of geometries was to determine how the quality of filament affects the mechanical behaviour of a 4-axis sample and a 5-axis sample. Examples of the multi-axis toolpaths used are illustrated in Figure 1, with the full toolpath for the dome requiring full 5 -axis motion. These geometries have been selected as they contain complex curved geometry that would be difficult to replicate using conventional MEX. The procedure for generating the G-code is presented in (Gardner et al., 2018; Kaill et al., 2019). These geometries have previously been used to compare 3-axis MEX against MAMEX, and indicated that the inclusion of additional axes improved the mechanical behaviour of the tested samples (Gardner et al., 2018; Kaill et al., 2019). As such, this aspect of MAMEX has not been covered in this paper since its purpose was to explore the effects of porosity on this multi axis technique.

Dome geometries are widely used in compression testing and they a suitable 3D dimensional geometry. Standard ISO test specimens would not suffice for this study as they are mainly 2-dimensional. Moreover, the mechanical behaviour of domes has been widely studied by other researchers, which is useful for comparison of results (Błachut, 2009; Easey et al., 2019; Gohari et al., 2012; Gupta and Gupta, 2009; Madhukar et al., 2014; Sindhuja, 2017; Zhang et al., 2019). 

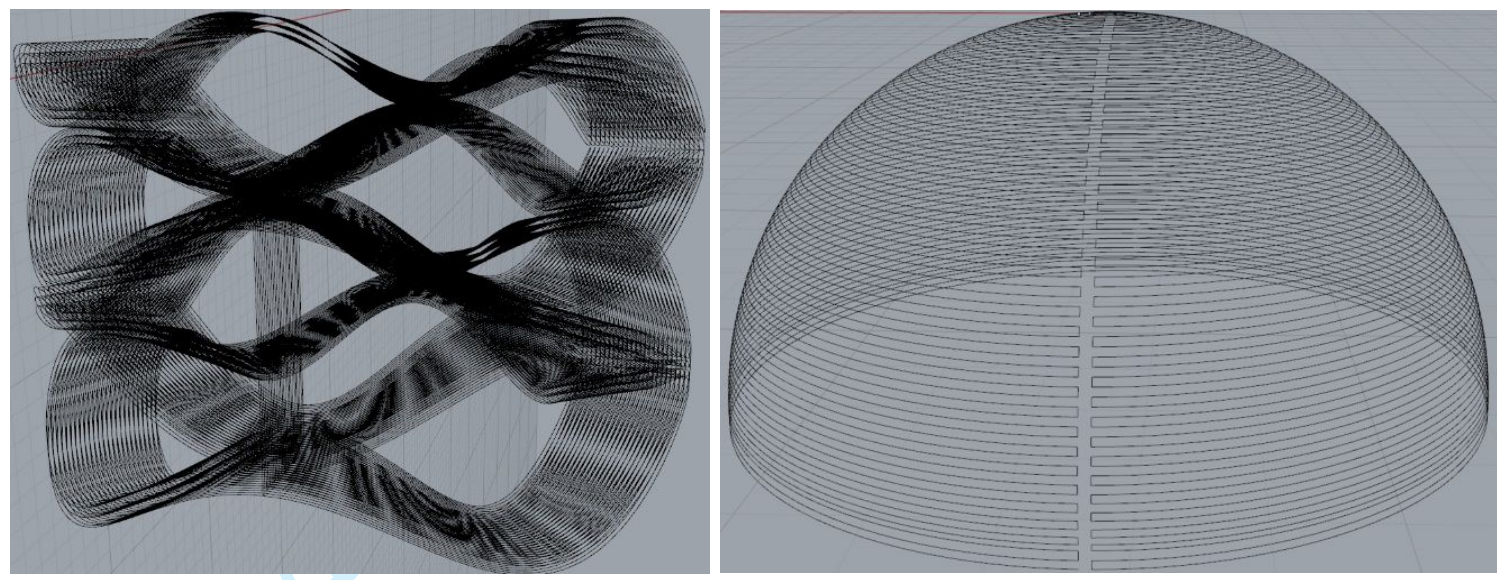

Figure 1 Axis Wave Spring Sample (Left), 5-Axis Dome Sample First Layer (Right)

\section{Materials}

The filaments used in this study were two different SCF-reinforced polylactic acid (SCFPLA). These filaments were sourced from different suppliers and will be referred to in this paper as SCF1 and SCF2. SCF1 was originally sourced for a previous study, during this study it was observed that the samples made with this material were lighter and displayed poorer mechanical behaviour when compared to unreinforced PLA samples.

This prompted further investigation of this filament's internal structure, as it behaved below expectations. The filament was found to have a much lower density than expected based on the manufacturers' stated percentage of carbon-fibre content. The relative density of this filament is shown in Table 1 . The density was calculated utilising a digital scale to weigh a known volume of the filament.

Following this analysis, a second SCF-PLA filament was sourced from an alternative supplier, this filament will be referred to as SCF2. The same material analysis was undertaken with this second filament as with the first. SCF2 was found to have a density that had a negligible difference when compared to its theoretical value, with its density being significantly greater than for pure PLA. The density of SCF2 is also shown in Table 1.

Table 1 Density and composition of the filaments

\begin{tabular}{|l|l|l|l|l|}
\hline ID & $\begin{array}{l}\text { Measured } \\
\text { Density }\left(\mathrm{kg} / \mathrm{m}^{3}\right)\end{array}$ & Base material & Reinforcement and wt\% & $\begin{array}{l}\text { Theoretical } \\
\text { Density }\left(\mathrm{kg} / \mathrm{m}^{3}\right)\end{array}$ \\
\hline SCF1 & 1205.67 & PLA (70\%) & Short Carbon-Fibre $(30 \%)$ & 1317 \\
\hline SCF2 & 1247.25 & PLA (80\%) & Short Carbon-Fibre $(20 \%)$ & 1248 \\
\hline
\end{tabular}

Following the analysis of the material density, a scanning electron microscope (SEM) was used to capture images of a cross-section of the stock material. The sample filaments of SCF1 and SCF2 were freeze-fractured via submersion in liquid nitrogen before fast fracturing of the sample. The purpose of this approach was to ensure that the internal composition of the filaments was exposed while minimising any damage to its internal structure.

During the imaging process, a noticeable defect was found within the SCF1 sample. A large concentration of air bubbles was observed in the centre of the cross-section. This is illustrated in Figure 2a, with several air bubbles concentrated towards the centre of the filament. These air bubbles are the most likely reason why SCF1 does not display the 
theoretical value for density. This is a clear sign of a poor quality SCF-PLA filament and is a direct result of an inadequate mixing method being used in the creation of this material (Figueiredo et al., 2013).

In comparison, the cross-section of the SCF2 filament shown in Figure $2 \mathrm{~b}$ does not indicate the same voids in SCF1. The absence of these would indicate that SCF2 was produced with the removal of air bubbles in the mixing process being considered. This would also explain why SCF2 has a higher measured density when compared to SCF1.

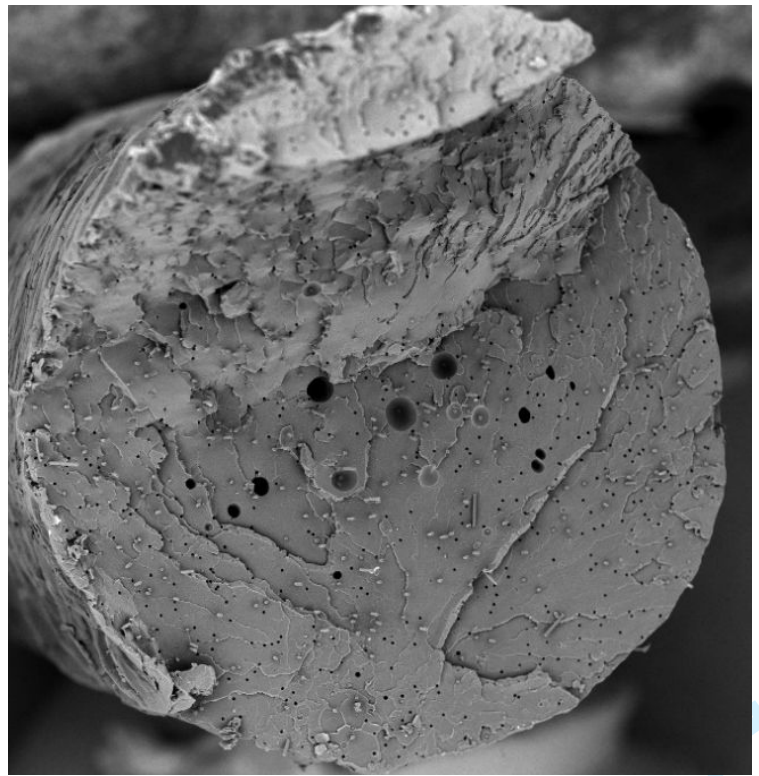

(a)

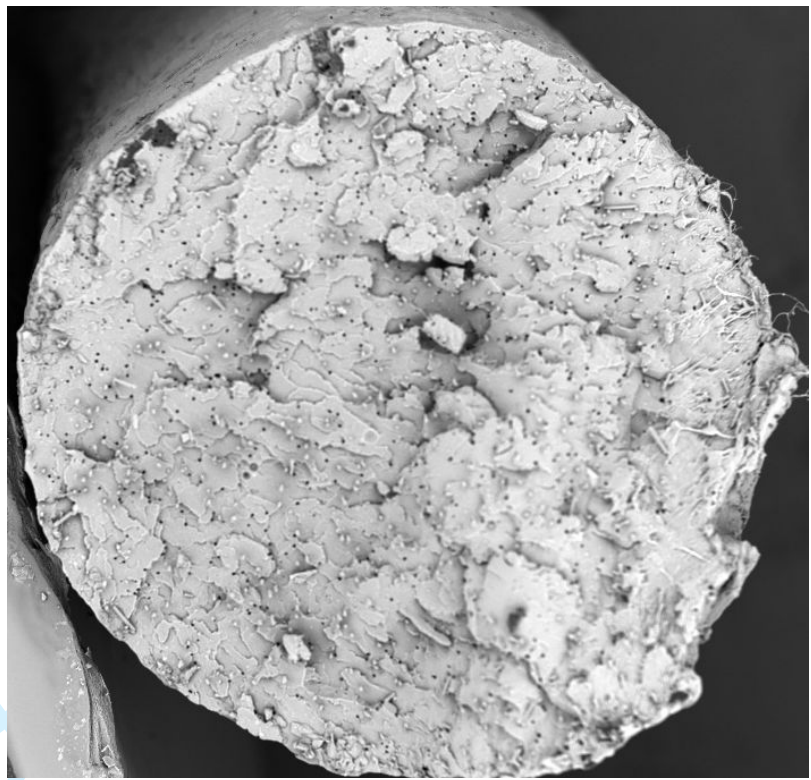

(b)

Figure 2: SEM of Filament Cross-section x60 Magnification - SCF1 (left), SCF2 (right)

\section{Sample fabrication and build parameters}

The dome samples were fabricated using a commercial 5-axis ME 3D printer (5axismaker $5 x m 600 X L)$ from 5axisworks Ltd (5axismaker, 2019a). The machine is shown in Figure 3. It is a system that can operate as a multi-axis milling machine in addition to its function as a multi-axis ME system.

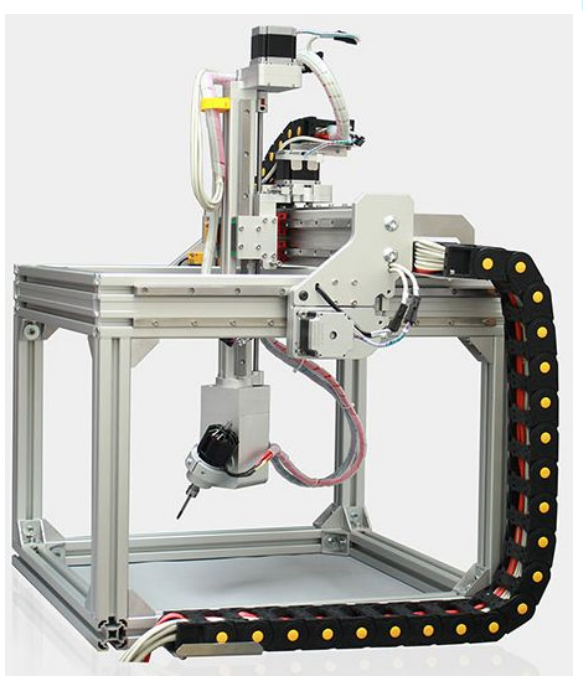

Figure 3: Multi-Axis ME System (5axismaker, 2019b) 
Grasshopper for Rhinoceros v5 was used as the slicing software and to generate the GCode from 3D CAD data.

For processing, the filament was melted and deposited at an extruder temperature of $210^{\circ} \mathrm{C}$ using a hardened steel nozzle with an exit diameter of $0.6 \mathrm{~mm}$. The hardened steel nozzle is required due to the abrasive nature of the carbon fibres. The reinforced samples were printed using the same tool path as the dome sample shown in Figure 1.

The melted filament expands in diameter after leaving the nozzle, resulting in an approximate hatch distance of $0.6 \mathrm{~mm}$ and a shell thickness of approximately $0.2 \mathrm{~mm}$. A printing speed of $70 \mathrm{~mm} / \mathrm{min}$ was adopted for the fabrication process.

In Table II, a summary of the sample description and build orientation is given, for convenience.

Table 2: Average Sample Data

\begin{tabular}{|l|l|l|}
\hline Sample & Average Mass $(\mathrm{g})$ & $\begin{array}{l}\text { Average Wall Thickness } \\
(\mathrm{mm})\end{array}$ \\
\hline SCF1 Wave Spring & 9.9 & 2.6 \\
\hline SCF2 Wave Spring & 11.42 & 2.6 \\
\hline SCF1 Dome & 2.27 & 1.06 \\
\hline SCF2 Dome & 2.32 & 1.06 \\
\hline
\end{tabular}

Samples were produced utilising the MAMEX system, following the same print procedure for each selected sample geometry. For each data set, 5 samples were created to reduce the risk and likelihood of any anomalous sample impacting the results of the overall study. The average mass and the wall thickness of the samples are shown in Error! Reference source not found.. The values recorded in Error! Reference source not found. illustrate how the discrepancy in the density of the filament directly influenced the mass of the samples produced. Samples produced with SCF1 were consistently lighter than samples produced with SCF2, even though they were specified as having a higher carbon fibre fraction. The wave spring samples had a mass difference of $15 \%$, which was higher than expected. The reason for this has not yet been fully understood and will be the subject of future investigations. The thin-walled dome samples have a difference of $3 \%$ in mass, this is in line with the difference in densities of the stock material. These samples, having been produced under the same conditions, were then subjected to the same mechanical testing procedure.

\section{Compression testing}

After the samples were built, axial compression testing was carried out using an Instron 3366 material test system with a $5 \mathrm{kN}$ load cell and a compression speed of $2 \mathrm{~mm}$.s -1 . The purpose of this test procedure was to establish the different mechanical behaviours of the test samples regarding stiffness, ductile behaviour and maximum compressive loading. The experimental setup for the testing is illustrated in Figure 4.

Compression testing of custom designed specimens was chosen because it results in a stress distribution that includes areas of compression, tension and bending. This was 
deemed to be more representative of real-world loading situations than pure tensile, compression or bending set-ups.

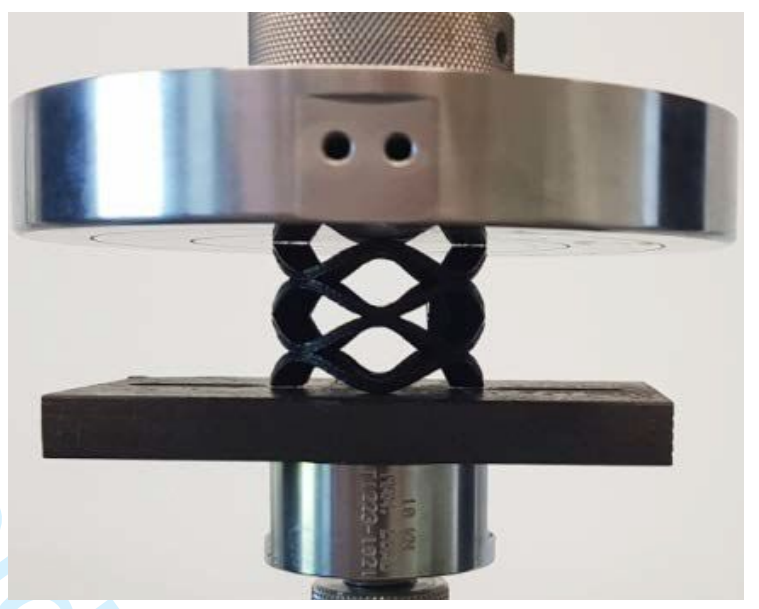

Figure 4: Compression Test Set-Up

The samples were tested until failure with the amount of force withstood being recorded relative to the displacement of the load cell.

\section{Results and discussion}

The samples were tested following the methodology previously outlined, and the average results are shown graphically in Figure 5. These results indicate that SCF2 displayed improved overall mechanical strength when compared to SCF1. With the SCF2 wave spring sample able to withstand $35 \%$ greater force than the SCF1 sample. For the dome samples, the SCF2 samples were able to withstand $15 \%$ more applied force before ultimate failure than the SCF1 samples. They were also able to withstand $35 \%$ greater deformation before failure.

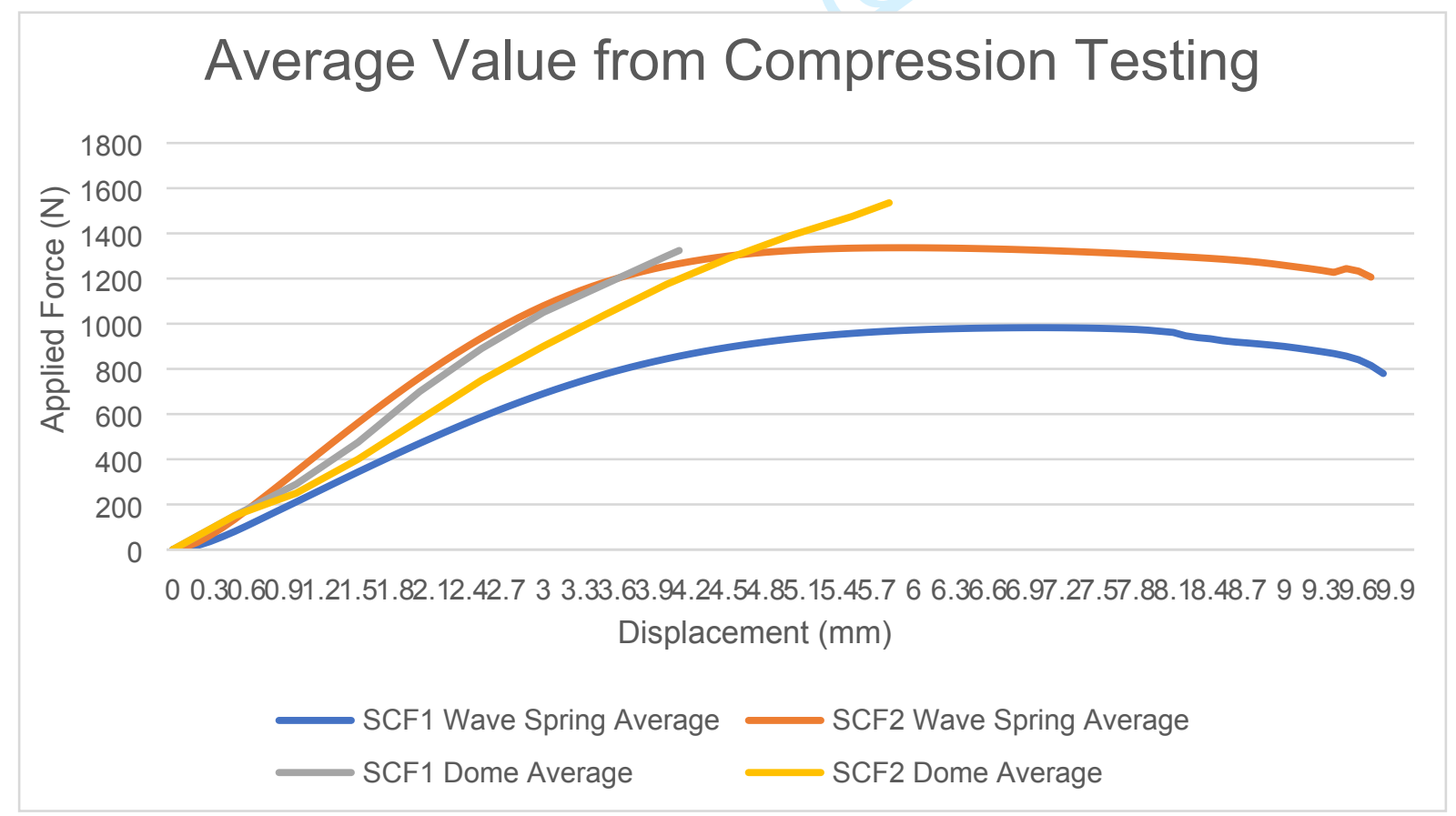

Figure 5: Average Results from Compression Testing 
To start to explore why the presence of voids and consequentially reduced density of the SCF1 material had such a pronounced effect on the sample's mechanical behaviour, a finite element analysis (FEA) study was undertaken. Figure 6 shows the FEA study performed on a section of the wave spring geometry. The purpose of this study was not to predict the maximum loading condition of the relevant geometries or at what load the geometries will begin to deform, as with typical uses of FEA. Rather, FEA was used to ascertain the orientation of the dominant stress vectors acting upon and within the geometry. This study highlights how approximately half of the sample's geometry is in tension, with the remainder being in compression.

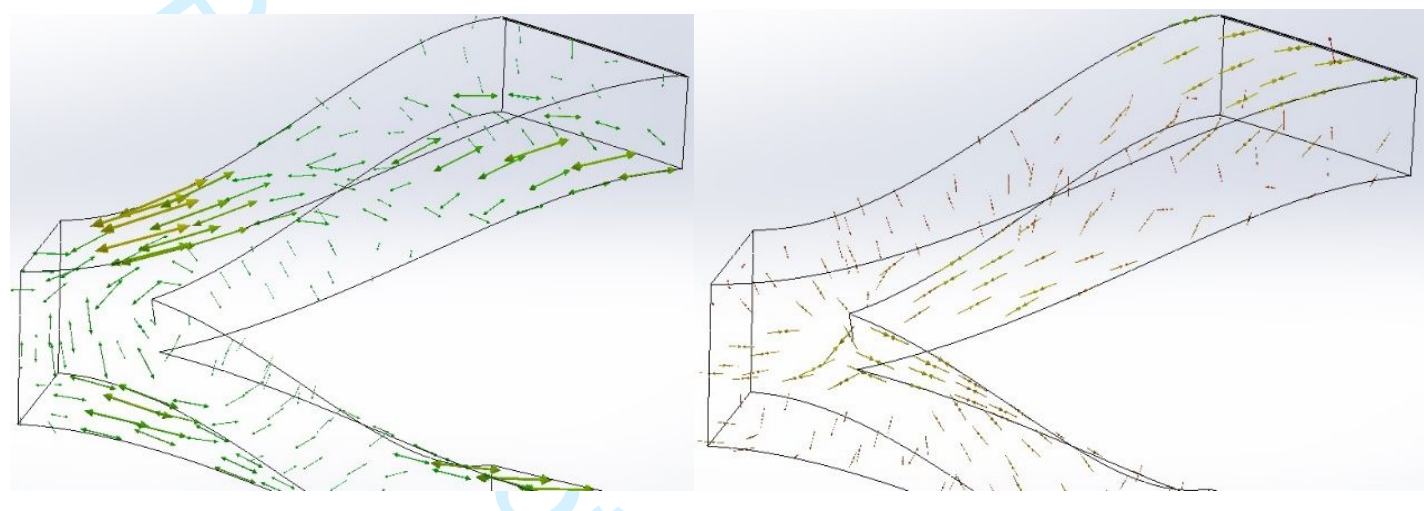

Figure 6: Dominant Stress Vectors Within Wave Spring Geometry

The prediction of the FEA would indicate that the samples should fail where the curved sections meet and fail due to the bending moments within the structure. This prediction does accurately represent how the wave spring failed in testing. The failure behaviour is illustrated in Figure 7, which shows a sample made in SCF2 after testing. The wave spring samples failed gradually when different sections of the wave spring began to give way, due to the load cell applying the compressive axial force. Any localised air-pockets within the structure would reduce the effective cross-sectional area, leading to earlier failure.

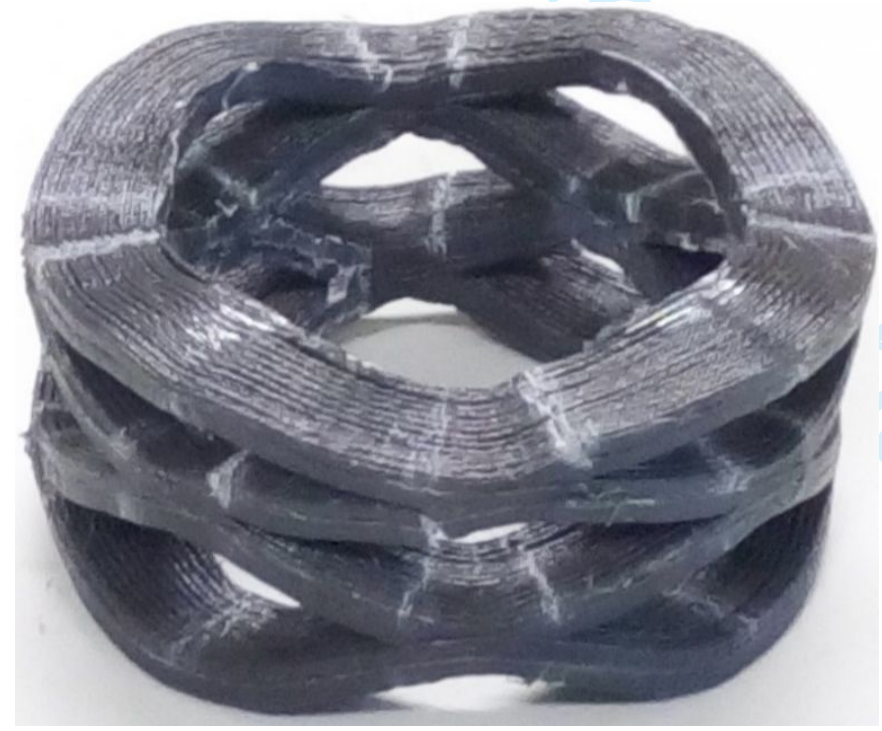

Figure 7: Failure Behaviour of Wave Spring Sample - Note multiple cracks at section convergence regions

SEM imaging was utilised to investigate the fracture surfaces of the samples, as shown in Figure 8 . In both images, it is possible to see that the bottom regions show signs of the material failing in tension since the SCFs have been pulled out of the polymer material 
matrix. The upper regions do not show these signs, indicating that they were in compression. This means that the two dominant stress vectors have acted on this sample parallel to each other as implied by the FEA analysis, with the samples undergoing a complex pattern of bending moments. The overall structure acts as a lattice structure of bending moments.
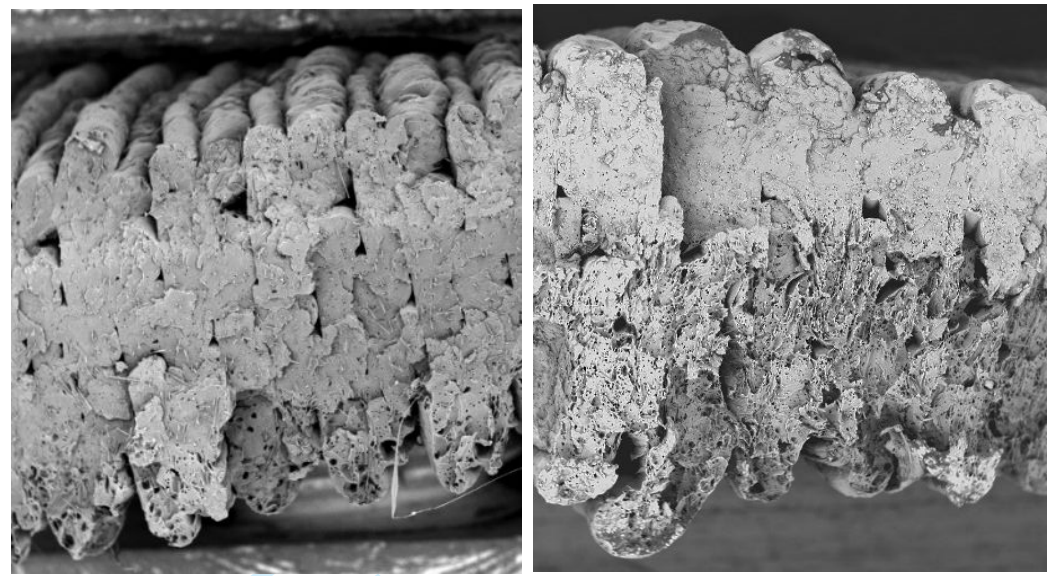

Figure 8: SEM Overview of Fracture Surface at x60 Magnification - SCF1 (Left), SCF2 (Right)

However, this does not adequately explain why the SCF1 samples displayed lower mechanical performance than the SCF2 samples. The SCF1 samples were examined under greater magnification, as shown in Figure 9. Small air-pockets where discovered around the short fibres, reducing their interaction with the material matrix. These would act as inclusions within the material matrix and cause substantial weakness, particularly under tension. This phenomenon could be due to poor "fibre wetting" during the manufacturing process of the filament.

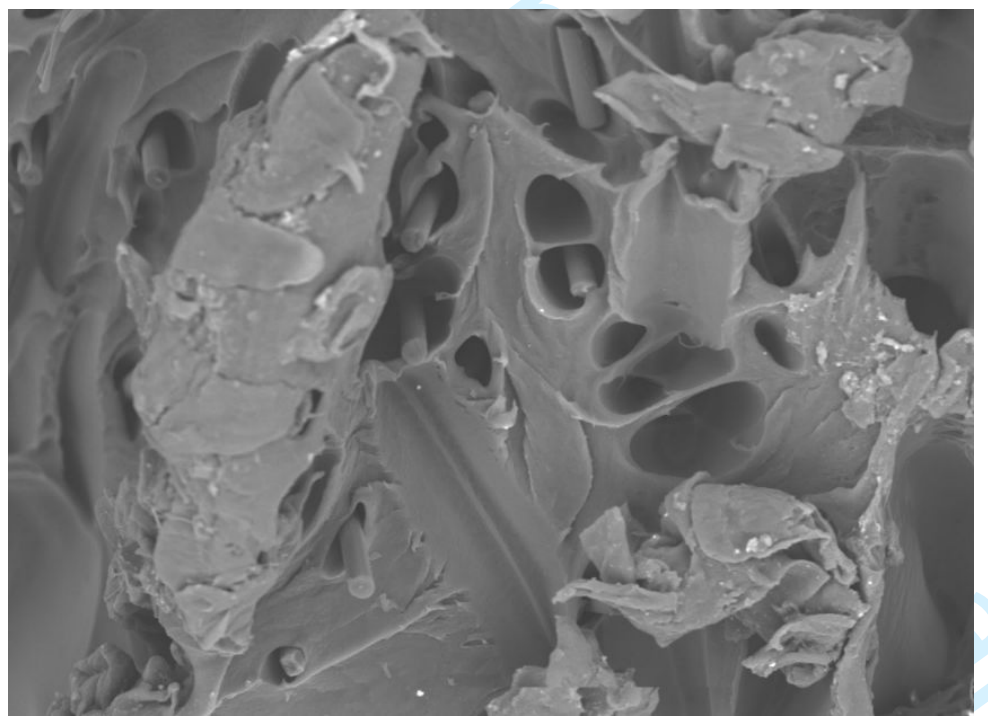

Figure 9: Section of SCF1 Sample Fracture Surface at x1000 Magnification

The mechanical behaviour of the thin-walled dome samples differed significantly when compared to the wave spring sample. The resulting graph shows that, rather than a gradual flattening-out and then reduction in the applied force before final failure, there is a more abrupt failure at the maximum applied force.

The failure behaviour of dome samples has been simulated by the Izmir institute of technology, with the dome predicted to roll into itself when subjected to compressive loading (Tasdemirci et al., 2015). This expected deformation behaviour follows the principal stress 


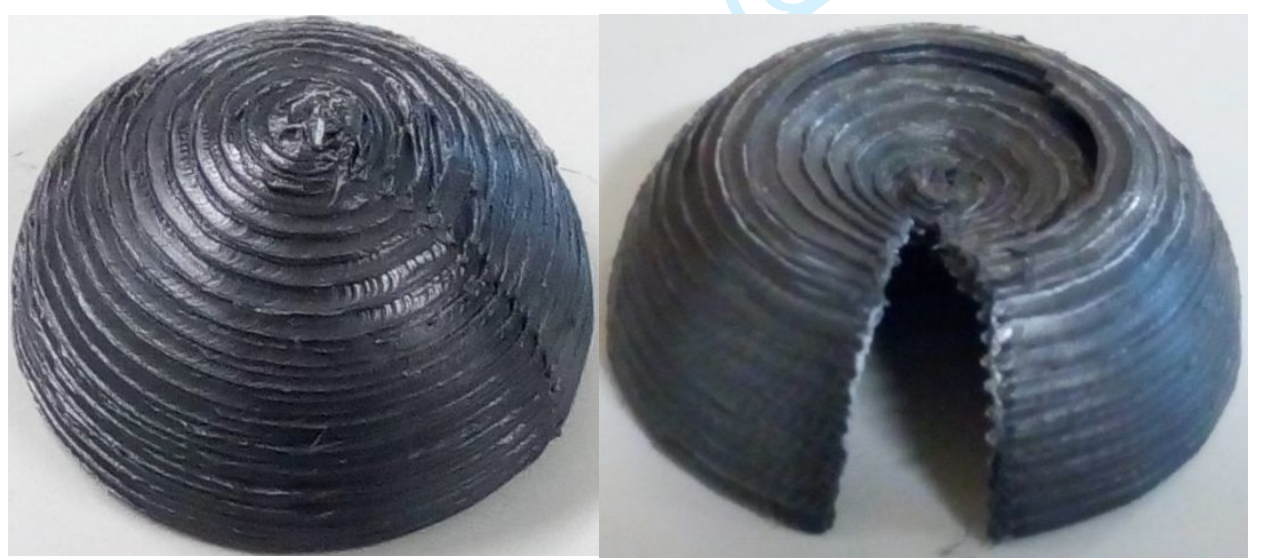

Figure 11: Failure Behaviour of Dome Samples - Sample Before Testing (Left), Sample After Testing (Right)

\section{Conclusions}

This work presents results for mechanical testing of materials produced by MAMEX. Two SCF-reinforced materials were investigated. Two sets of specimens were printed and tested, a dome sample and a wave spring part. 
The results have highlighted how the inclusion of voids within the filament used for printing can affect the mechanical behaviour of samples. A specific focus has been placed on how it affects structures created which utilise a multi-axis material extrusion system.

Referring to Figure 5, the SCF material that has a higher density does improve the mechanical behaviour of the samples. However, its impact is not as significant in a fully 5axis sample as the improved density could not be fully explored due to the design flaw in the tool path.

By utilising a full 5-axis print strategy it is possible to align short fibres in the direction of the principal stress vectors. The 4-axis wave spring samples also demonstrated how the increase in relative void concentration affected the mechanical behaviour. Both sets of samples made with void-free material demonstrating noticeably better mechanical strength, an average of $35 \%$ greater for the wave spring samples.

Further research should be carried out in this field with a variety of materials and fibre reinforcements, to determine which combination can benefit most from 5-axis MEX. A limitation of this research was that the machine used could not always deposit material in a way that would most benefit the mechanical behaviour. A machine with a greater range of movement and control would not require unwanted reversals of the direction of rotational travel. This will be addressed in future research studies, where possible.

Following this study, further research is ongoing in this field to explore the viability of multiaxis material extrusion techniques and technologies. The overall goal of this research is to establish design principles that would enable the creation of parts with improved mechanical behaviour.

\section{Acknowledgement}

The work contained within this study was partly supported through the European Commission as part of the DiCoMI project (Grant agreement ID: 778068).

\section{References}

5axismaker. (2019a), “5-Axis Printer”, available at: http://www.5axismaker.com/.

5axismaker. (2019b), "5-Axis Printer".

Al Abadi, H., Thai, H.T., Paton-Cole, V. and Patel, V.I. (2018), "Elastic properties of 3D printed fibre-reinforced structures", Composite Structures, Elsevier, Vol. 193 No. March, pp. 8-18.

Ahn, S., Montero, M., Odell, D., Roundy, S. and Wright, P.K. (2002a), "Anisotropic material properties of fused deposition modeling ABS", Rapid Prototyping Journal, MCB UP Ltd, Gyeongsang National University, Jinju, 660-701, South Korea, Vol. 8 No. 4, pp. 248257.

Ahn, S., Montero, M., Odell, D., Roundy, S. and Wright, P.K.K. (2002b), "Anisotropic material properties of fused deposition modeling ABS", Rapid Prototyping Journal, MCB UP Ltd, Gyeongsang National University, Jinju, 660-701, South Korea, Vol. 8 No. 4, pp. 248257.

Anwer, A. and Naguib, H.E. (2018a), "Multi-functional flexible carbon fiber composites with controlled fiber alignment using additive manufacturing", Additive Manufacturing, Elsevier, Vol. 22 No. July 2017, pp. 360-367. 
Anwer, A. and Naguib, H.E. (2018b), "Multi-functional flexible carbon fiber composites with controlled fiber alignment using additive manufacturing", Additive Manufacturing, Elsevier, Vol. 22 No. July 2017, pp. 360-367.

Bellini, A. and Güçeri, S. (2003), "Mechanical characterization of parts fabricated using fused deposition modeling", Rapid Prototyping Journal, MCB UP Ltd, Vol. 9 No. 4, pp. 252264.

Błachut, J. (2009), "Buckling of multilayered metal domes", Thin-Walled Structures, Vol. 47 No. 12 , pp. $1429-1438$.

Blok, L.G., Longana, M.L., Yu, H. and Woods, B.K.S. (2018), "An investigation into 3D printing of fibre reinforced thermoplastic composites", Additive Manufacturing, Vol. 22 No. March, pp. 176-186.

Carlota, V. (2019), "University of Maine creates the world's largest 3D printed boat", 3D Natives, available at: https://www.3dnatives.com/en/3d-printed-boat-university-ofmaine-161020195/ (accessed 25 November 2019).

Damon, J., Dietrich, S., Gorantla, S., Popp, U., Okolo, B. and Schulze, V. (2019), "Process porosity and mechanical performance of fused filament fabricated 316L stainless steel", Rapid Prototyping Journal, Vol. 25 No. 7, pp. 1319-1327.

Dickson, A.N., Barry, J.N., McDonnell, K.A. and Dowling, D.P. (2017), "Fabrication of continuous carbon, glass and Kevlar fibre reinforced polymer composites using additive manufacturing", Additive Manufacturing, Elsevier B.V., Vol. 16, pp. 146-152.

Le Duigou, A., Castro, M., Bevan, R. and Martin, N. (2016), "3D printing of wood fibre biocomposites: From mechanical to actuation functionality", Materials \& Design, Vol. 96, pp. 106-114.

Easey, N., Chuprynyuk, D., Musa, W.M.S.W., Bangs, A., Dobah, Y., Shterenlikht, A. and Scarpa, F. (2019), "Dome-shape auxetic cellular metamaterials: Manufacturing, modeling, and testing", Frontiers in Materials, Vol. 6 No. April, pp. 1-13.

Ferreira, R.T.L., Amatte, I.C., Dutra, T.A. and Bürger, D. (2017), "Experimental characterization and micrography of 3D printed PLA and PLA reinforced with short carbon fibers", Composites Part B: Engineering, Elsevier Ltd, Vol. 124, pp. 88-100.

Figueiredo, J.L., Bernardo, C.A., Baker, R.T.K. and Hüttinger, K.J. (2013), Carbon Fibers Filaments and Composites, Springer Netherlands, available at: https://books.google.co.uk/books?id=MgHxCAAAQBAJ.

"Gantri". (2018), , available at: https://www.gantri.com/.

Gardner, J.A., Kaill, N., Campbell, R.I., Bingham, G.A., Engstrøm, D.S. and Balc, N.O. (2018), "Aligning Material Extrusion Direction with Mechanical Stress via 5-Axis Tool Paths", pp. 2005-2019.

Gardner, J.D. (2018), “Curved Layers”, DiCoMI, available at: http://www.dicomi.eu/.

Gohari, S., Golshan, A., Bassiri Nia, A. and Hashemzadeh, M. (2012), "Prediction of failure in thin-walled hemispherical GRP dome subjected to static internal pressure based on a failure factor", Advanced Materials Research, Vol. 488-489 No. March, pp. 358-366.

Gupta, P.K. and Gupta, N.K. (2009), "A study of axial compression of metallic hemispherical domes”, Journal of Materials Processing Technology, Vol. 209 No. 4, pp. 2175-2179. 
Hoglund, R. and Smith, D.E. (2015), "Non-Isotropic Material Distribution Topology Optimization for Fused Deposition Modeling Products", Proceeding of the 2015 Solid Freeform Fabrication Symposium, Vol. 88, Austin, Texas, available at:https://doi.org/10.1017/CBO9781107415324.004.

Kaill, N., Campbell, R.I., Pradel, P. and Bingham, G. (2019), "A Comparative Study Between 3-Axis and 5-Axis Additively Manufactured Samples and Their Ability to Resist Compressive Loading", Solid Freeform Fabrication 2019: Proceedings of the 30th Annual International.

Koch, C., Van Hulle, L. and Rudolph, N. (2017a), "Investigation of mechanical anisotropy of the fused filament fabrication process via customized tool path generation", Additive Manufacturing, Elsevier B.V., Vol. 16, pp. 138-145.

Koch, C., Van Hulle, L. and Rudolph, N. (2017b), "Investigation of mechanical anisotropy of the fused filament fabrication process via customized tool path generation", Additive Manufacturing, Elsevier B.V., Vol. 16, pp. 138-145.

Lee, M. (2019), Design for Additive Manufacturing (DfAM) of Large Size Products Using a Plastic Pellet Extrusion: Case Study of the Excavator Cabin Production, Ulsan National Institute of Science and Technology.

Li, N., Li, Y. and Liu, S. (2016), "Rapid prototyping of continuous carbon fiber reinforced polylactic acid composites by 3D printing", Journal of Materials Processing Technology, Elsevier B.V., Vol. 238, pp. 218-225.

Lithgow, D., Morrison, C., Pexton, G., Panarotto, M., Müller, J.R., Almefelt, L. and McLaren, A. (2019), "Design Automation for Customised and Large-Scale Additive Manufacturing: A Case Study on Custom Kayaks", Proceedings of the Design Society: International Conference on Engineering Design, Vol. 1 No. 1, pp. 699-708.

Madhukar, A., Perlitz, D., Grigola, M., Gai, D. and Jimmy Hsia, K. (2014), "Bistable characteristics of thick-walled axisymmetric domes", International Journal of Solids and Structures, Elsevier Ltd, Vol. 51 No. 14, pp. 2590-2597.

McLouth, T.D., Severino, J. V, Adams, P.M., Patel, D.N. and Zaldivar, R.J. (2017a), "The impact of print orientation and raster pattern on fracture toughness in additively manufactured ABS", Additive Manufacturing, Elsevier B.V., Vol. 18, pp. 103-109.

McLouth, T.D., Severino, J. V, Adams, P.M., Patel, D.N. and Zaldivar, R.J. (2017b), "The Impact of Print Orientation and Raster Pattern on Fracture Toughness in Additively Manufactured \{ABS\}", Additive Manufacturing, Elsevier B.V., Vol. 18, p. .

Mei, H., Ali, Z., Yan, Y., Ali, I. and Cheng, L. (2019), "Influence of mixed isotropic fiber angles and hot press on the mechanical properties of 3D printed composites", Additive Manufacturing, Vol. 27 No. March, pp. 150-158.

Moetazedian, A., Gleadall, A., Han, X. and Silberschmidt, V. V. (2020), "Effect of environment on mechanical properties of 3D printed polylactide for biomedical applications", Journal of the Mechanical Behavior of Biomedical Materials, Elsevier Ltd, Vol. 102, p. 103510.

Mohammed, M.I. and Fay, P. (2018), "Design and additive manufacturing of a patient specific polymer thumb splint concept", Solid Freeform Fabrication 2018: Proceedings of the 29th Annual International Solid Freeform Fabrication Symposium- An Additive Manufacturing Conference, No. November, pp. 873-886. 
Naranjo-Lozada, J., Ahuett-Garza, H., Orta-Castañón, P., Verbeeten, W.M.H. and SáizGonzález, D. (2019), "Tensile properties and failure behavior of chopped and continuous carbon fiber composites produced by additive manufacturing", Additive Manufacturing, Elsevier, Vol. 26 No. August 2018, pp. 227-241.

Ning, F., Cong, W., Hu, Y. and Wang, H. (2017), "Additive manufacturing of carbon fiberreinforced plastic composites using fused deposition modeling: Effects of process parameters on tensile properties", Journal of Composite Materials, Vol. 51 No. 4, pp. 451-462.

Ning, F.D., Cong, W.L., Qiu, J.J., Wei, J.H. and Wang, S.R. (2015), "Additive Manufacturing of Carbon Fiber Reinforced Thermoplastic Composites using Fused Deposition Modeling", Composites Part B: Engineering, Vol. 80, American Society of Mechanical Engineers, pp. A7-A15.

Novak, J.I. and O'Neill, J. (2019), "A design for additive manufacturing case study: fingerprint stool on a BigRep ONE", Rapid Prototyping Journal, No. April, available at:https://doi.org/10.1108/RPJ-10-2018-0278.

Papon, E.A. and Haque, A. (2019), "Fracture toughness of additively manufactured carbon fiber reinforced composites", Additive Manufacturing, Elsevier, Vol. 26 No. September 2018, pp. 41-52.

Paterson, A.M., Bibb, R.J., Campbell, R.I. and Bingham, G. (2015), "Comparing additive manufacturing technologies for customised wrist splints.", Rapid Prototyping Journal, Emerald Group Publishing Ltd., School of Materials, University of Manchester, Manchester, United Kingdom, Vol. 21 No. 3, pp. 230-243.

Shen, H., Diao, H., Yue, S. and Fu, J. (2018a), "Fused deposition modeling five-axis additive manufacturing: machine design, fundamental printing methods and critical process characteristics", Rapid Prototyping Journal, Vol. 24 No. 3, pp. 548-561.

Shen, H., Diao, H., Yue, S. and Fu, J. (2018b), "Fused deposition modeling five-axis additive manufacturing: machine design, fundamental printing methods and critical process characteristics", Rapid Prototyping Journal, Vol. 24 No. 3, pp. 548-561.

Shofner, M.L., Lozano, K. and Rodrı, F.J. (2002), "Nanofiber-Reinforced Polymers Prepared by Fused Deposition Modeling”, Journal of Applied Polymer Science, Vol. 89, pp. 30813090.

Sindhuja, M. (2017), "Stress and Buckling Based Design for a Hemispherical Dome", International Journal for Research in Applied Science and Engineering Technology, Vol. V No. VIII, pp. 887-895.

Sun, Q., Rizvi, G.M., Bellehumeur, C.T. and Gu, P. (2008), "Effect of processing conditions on the bonding quality of FDM polymer filaments", Rapid Prototyping Journal, Emerald Group Publishing Limited, Vol. 14 No. 2, pp. 72-80.

Tasdemirci, A., Sahin, S., Kara, A. and Turan, K. (2015), "Crushing and energy absorption characteristics of combined geometry shells at quasi-static and dynamic strain rates: Experimental and numerical study", Thin-Walled Structures, Elsevier, Vol. 86, pp. 8393.

Tekinalp, H.L. and Al, E. (2014), "Highly oriented carbon fiber - polymer composites via additive manufacturing", Composites Science and Technology, Vol. 105 No. September 2015, pp. 144-150. 
Vaezi, M. and Yang, S. (2015), "Extrusion-based additive manufacturing of PEEK for biomedical applications", Virtual and Physical Prototyping, Taylor \& Francis, Vol. 10 No. 3, pp. 123-135.

Wang, J., Xie, H., Weng, Z., Senthil, T. and Wu, L. (2016), "A novel approach to improve mechanical properties of parts fabricated by fused deposition modeling", Materials and Design, Elsevier Ltd, Vol. 105, pp. 152-159.

Wang, X., Jiang, M., Zhou, Z., Gou, J. and Hui, D. (2017), "3D printing of polymer matrix composites: A review and prospective", Composites Part B: Engineering, Elsevier Ltd, Vol. 110, pp. 442-458.

Weon, J.I., Gam, K.T., Boo, W.J. and Sue, H.J. (2006), "Impact-toughening mechanisms of calcium carbonate-reinforced polypropylene nanocomposite", Journal of Applied Polymer Science, Vol. 99 No. 6, pp. 3070-3076.

Wulle, F., Coupek, D., Schäffner, F., Verl, A., Oberhofer, F. and Maier, T. (2017), "Workpiece and Machine Design in Additive Manufacturing for Multi-Axis Fused Deposition Modeling", Procedia CIRP, Elsevier B.V., Vol. 60, pp. 229-234.

Zhang, J., Wang, Y., Tang, W., Zhu, Y. and Zhao, X. (2019), "Buckling of externally pressurised spherical caps with wall-thickness reduction", Thin-Walled Structures, Elsevier Ltd, Vol. 136 No. July 2018, pp. 129-137.

Zhang, W., Cotton, C., Sun, J., Heider, D., Gu, B., Sun, B. and Chou, T.W. (2018), "Interfacial bonding strength of short carbon fiber/acrylonitrile-butadiene-styrene composites fabricated by fused deposition modeling", Composites Part B: Engineering, Elsevier, Vol. 137 No. October 2017, pp. 51-59.

Zhang, Y., De Backer, W., Harik, R. and Bernard, A. (2016), "Build Orientation Determination for Multi-material Deposition Additive Manufacturing with Continuous Fibers", Procedia CIRP, The Author(s), Vol. 50, pp. 414-419.

Zhong, W., Li, F., Zhang, Z., Song, L. and Li, Z. (2001), "Short fiber reinforced composites for fused deposition modeling", Materials Science and Engineering A, Vol. 301. 